\title{
THE ROLE OF SUBNIVEAN ACCESS IN WINTER \\ HABITAT SELECTION OF MARTEN \\ IN YELLOWSTONE NATIONAL PARK
}

Stuart Sherburne

John Bissonette

Utah Cooperative Fish and Wildlife Research Unit

Utah state University

Logan

\section{objectives}

This research project has two primary goals. The first is to determine home range spatial dynamics of marten (Maxes americana) in Yellowstone relative to habitat type. Results of this analysis will aid in the understanding of marten habitat selection.

The study's second goal is aimed at identifying the habitat variables that influence subnivean access. A proximate factor analysis of subnivean access behavior will be conducted to determine the components that make old growth suitable for marten. Results from both objectives will allow assessment of the effects of the 1988 fires in Yellowstone on marten habitat.

\section{Methods}

The methodology discussed below relates only to the two primary objectives.

The first objective will be addressed through the use of radio telemetry and snow tracking data. Telemetry data will be analyzed using a bootstrap program to determine home range dynamics. Snow tracking will be used to confirm telemetry data and locate subnivean access points.

The second objective will be examined by using snow tracking data. Habitat variables to be measured include overhead cover, snow depth, cover type, downed woody debris and subnivean prey densities. Access points located through snow tracking will be marked and habitat variables measured. Random transects will be run through a variety of habitat types to determine if these habitats are used by marten. Habitat variables will be measured in un-used habitat and 
values compared to those from used habitat. Multivariate analysis will be used to compare values from different habitat types and to identify if features of used access points are significantly different from potentially available access points in unused habitat.

Field work begins in January of 1990. There will be two winter and two summer field seasons. Preliminary data analysis will begin in the fall of 1990. Data analysis completion and a final report are targeted for June of 1992 . 